\title{
Inflationary effects of monetary policies in newly industrialized economies with cross-sectoral labor and capital immobility
}

\author{
Anindya S. Chakrabarti \\ Economics area \\ Indian Institute of Management \\ Vastrapur, Ahmedabad 380015, India \\ Email address: anindyac@iimahd.ernet.in
}

August 17, 2015 
Running title: Inflation with immobile labor and capital

\section{Corresponding author:}

Anindya S. Chakrabarti

Economics area

Indian Institute of Management

Vastrapur, Ahmedabad 380015, India

Email address: anindyac@iimahd.ernet.in 


\begin{abstract}
This paper studies the effects of monetary policies in newly industrialized economies characterized by extremely low level of labor and capital mobility between urban and rural sectors. Policies are executed in the urban sector which sends waves of adjustments in the rest of the economy. I show that with liquidity constraints and immobility in labor and capital, the sectorspecific effects are markedly different from those in a one-sector economy. In particular, they are asymmetric and the rural sector lags behind the urban sector during the adjustment process. This explains temporary phases of significantly high inflation with uneven sectoral effects which often accompany major reforms in the banking and monetary institutions of such economies, e.g. in case of India. Finally, as the consumption patterns alter in such an economy undergoing structural changes, the sectoral distribution of liquidity is affected inducing dissimilar responses to shocks, both within and between sectors.
\end{abstract}

Keywords: Newly industrialized economy, market rigidity, frictions, sticky price, liquidity shocks. 


\section{Introduction}

A common feature of the newly industrialized countries like India is that they essentially consist of two sectors, a formal urban sector and an informal rural sector. Usually the former specializes in a combination of manufacturing and service products (both high and low-end) whereas the latter specializes almost exclusively on agricultural goods and low-end services. Such a segmentation can be interpreted as the middle phase of the process of economic growth which is accompanied by deep changes in consumption and production patterns reflecting long-term shift away from agriculture to manufacturing and eventually to service economy. However, when devising policies distributional consequences receive little attention (Prasad [2014]). Due to labor market rigidity and severe incompleteness of the financial markets, households have different abilities and ways to smooth consumption and often the responses to policy shocks are not in sync across sectors. Thus an important policy question would be to understand the contemporaneous adjustment processes across sectors in short-run.

From a long run perspective, developed economies have undergone such structural changes to a large degree. Economies in the process of development are experiencing these changes which requires substantial amount of sectoral reallocation of labor and capital. Therein lies the problem of multiple types of frictions inhibiting cross-sector free flows of labor and capital. I argue in this paper that when those frictions are significantly high making the economy effectively disaggregated in terms of capital and labor markets, short run effects of monetary policies have sector-specific effects which are substantially different from a single sector economy both in terms of propagation of shocks and aggregate effects on macro variables.

Broadly speaking, this structural evolution goes by the name of Kuznets facts (Kuznets [1957]) which emphasize the unbalanced growth process of the economies. For most of the developed countries the current transition is from manufacturing to service. However, for the developing world in general, the current phase is transitioning from agriculture to both manufacturing and service simultaneously (for example, India). In such countries, there is a huge sectoral divide in terms of labor mobility as sectoral reallocation of labor input involves substantial amount of fixed cost for building up human capital. Complementing it, access to asset markets are also very different between the agricultural workers (rural) and the rest of the economy (urban) where the latter dominates the earlier. To have some perspective of 
the magnitude of labor allocation in India, see Table 1 which shows almost equal division between agriculture and the manufacturing/service economy. The next table (Table 2) shows that in nominal terms the access of urban vs. rural households in the formal financial markets are dominated by the former although as shares of income, the propensity to access financial assets are similar. Such considerations bring up a question on how to devise monetary policies to control inflation in such economies where a huge fraction of households are extremely under-banked, virtually disconnected from the mainstream economy (e.g. Mehrotra and Yetman [2014]; Bilbie [2008]; Bartolomeo and Rossi [2007]). The inflationary experience of India can shade some light here. Annual inflation of consumer prices in India (Ref. World Bank) shot up from $3.76 \%$ in 2004 to almost $12 \%$ in 2010 before coming down to $6.35 \%$ in 2014 . This decade long episode of high inflation was preceded by a period five to six years of low inflation. Thus it came as a puzzle as to what changed during this specific period causing the spell of inflation.

Financial coverage of India is significantly underdeveloped e.g., Subbarao [2011] documents that out of nearly 600000 human settlements in India only 30000 were served, even those served often had inadequate measures. In that backdrop, Basu [2011] argued emphatically that with the banking network spreading extensively in the last few years, a huge amount of the idle assets lying out of reach now, will be used actively in the economy potentially creating inflationary pressure. An interesting fact is that this episode of financial inclusion also took off during the same phase in response to the hugely under-banked population of India. Thus there was a substantial increase in banks' outreach to the dormant money that rural workers would save under the mattress. By pulling those assets into circulation, the process of financial inclusion could generate inflation purely through quantity channel though that would be a short-term phenomenon rather than a long-term one. Once the prices catch-up with the increased volume of money, the inflationary pressure would stop. Although this seems to be a negative impact of financial inclusion, the potential benefit from financial inclusion outweighs the cost (Basu [2011]). The point made in this paper is to recognize such a channel of inflation.

In this paper, we first develop a formal framework to expound that idea and then we show that this phenomena can indeed manifest in terms of short term phase of high inflation. But the long run consequences are not substantial. To the best of the author's knowledge, this is one of the first attempts to decompose inflationary effects across sectors by characterizing 


\begin{tabular}{|l|l|l|}
\hline Sector & Total population (mi) & Per capita income (Rs. per year) \\
\hline Agriculture & 437.9 & 9518 \\
\hline Industry & 97.8 & 14411 \\
\hline Services & 491.5 & 15858 \\
\hline
\end{tabular}

Table 1: Sectoral composition of India. Source: NSHIE 200405 (data: NCAERCMCR analysis; adapted from Shukla [2010]).

\begin{tabular}{|l|l|l|}
\hline & Rural (Rs. per year) & Urban (Rs. per year) \\
\hline Household income & 51922 & 95827 \\
\hline Household expediture & 40124 & 68352 \\
\hline Financial investment & 1217 & 3857 \\
\hline Physical investent & 2886 & 5912 \\
\hline Others & 7694 & 17706 \\
\hline
\end{tabular}

Table 2: Investment composition of India. Source: NSHIE 200405 (data: NCAERCMCR analysis; adapted from Shukla [2010]). Investments in the stock markets are accounted for in the category of financial investment.

cross-sector liquidity flow in a DSGE setup. We show that the sector-specific effects of liquidity shocks are substantially different from a standard onesector model. The sectoral dispersions are seen to arise because of the trading structure between the urban and the rural households. Finally, we show that there are effects of structural change on the sectoral effectiveness of monetary shocks. But no dramatic change occurs.

The economy we consider has a dual sector characterized by negligible inter-sectoral labor and capital mobility. Fig. 1 describes a very stylized version of such an economy operating in autarky. The urban economy manufactures goods and produces both high-end (e.g. financial) and low-end (e.g. haircuts, transportation) services. The rural economy produces agricultural goods which are traded for low-end services and they also produce and consume 'land service' which incorporates natural as well as man-made resources. Similar to labor mobility, there exists virtually zero flow of financial assets. The urban households consume a bundle of manufactured goods (non-tradable), service and agricultural products whereas the rural households derive utility from a bundle of land services (non-tradable), service and 


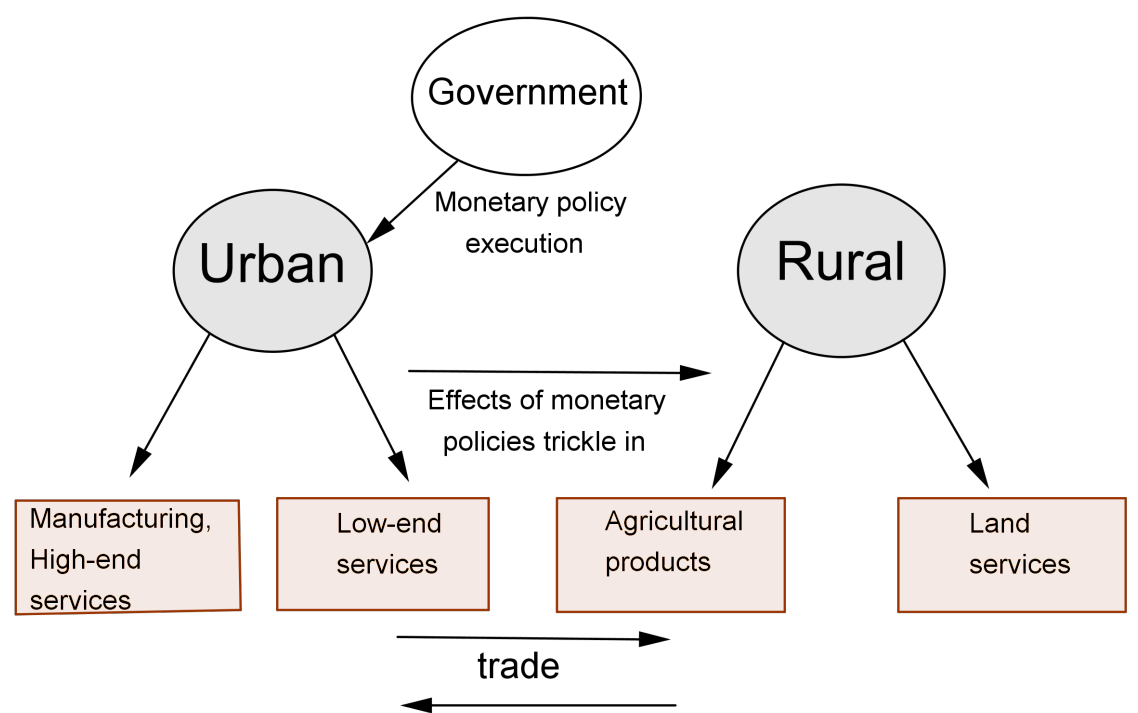

Figure 1: A diagramatic representation of a stylized economy with urbanrural divide. For simplicity, we do not differentiate between the monetary authority and the government.

agricultural products. The financial authority executes the monetary policies in the urban economy. The repercussions are felt in the rural economy later. However, the spread of the financial market (e.g. large-scale opening of bank branches) constitute a monetary shock given to the rural sector. For the purpose of the present exercise, we do not differentiate between the monetary authority and the government.

In terms of literature, this paper relates to three strands of it. In regards to the modeling exercise, the most relevant work is by Midrigan and Philippon [2011] who studied a monetary economy with multiple participant states and characterized the responses of real variables to monetary shocks. They concluded that there is substantial difference in the responses depending on the exact macroeconomic conditions of individual states. On a similar note, Williamson [2008] studied effects of monetary policies in an economy with segmented goods markets. It shows that money supply shock creates persistent responses of real variables. In our model, non-neutrality of money is due to sticky-prices as in Calvo [1983]. In our model, urban and rural economies are described by standard medium-scale neo-Keynesian DSGE models cap- 
turing the long-run view of the consumers as well as the capital formation processes in the respective economies. They are connected by a set of relationships depicting flow of goods and services due to trade and the resultant flow of money. The flow equations and the descriptive structure was introduced and analyzed by Chakrabarti [2015] in the context of international trade.

Second,many authors have studied monetary policies with limited participation. Mehrotra and Yetman [2014] provides a theoretical framework to analyze optimal monetary policies with hand-to-mouth agents along with usual consumption-smoothing agents. Bilbie [2008] shows that with sufficiently limited participation in the asset markets, there is a possibility that the slope of the IS curve (in the Keynesian sense) would revert. Bartolomeo and Rossi [2007] studies the same in a DSGE set up and shows that actually monetary policy becomes more effective when participation drops. In general, prevailing literature which emphasizes the interest rate channel for effectiveness of monetary policies by changing the opportunity cost of consumption. In contrast to that, a purely quantity theoretic channel is emphasized here. Also, instead of assuming literally hand-to-mouth agents, we assume that the rural households have access to different types of capital stocks (Rosenzweig and Wolpin [1993]) through which they can smooth consumption.

Third, it also relates to the literature on structural change. The initial literature modeled the dramatic structural evolution in the form of labor allocation. Baumol [1967] was one of the very first attempts to model unbalanced growth and the resultant macroeconomic effects (see also Pasinetti [1981]). Laitner [2000] relates evolution of the average propensity to save with the process of industrialization in an economy producing agricultural and manufactured goods. As people move away from consumption of agricultural to manufactured goods, land becomes less important leaving physical capital to have a bigger share in the national income. Echevarria [1997] relates structural evolution to growth in a dynamic general equilibrium set-up. A common theme of this strand of the literature is that the driver of structural change is non-homotheticity of preferences. Ngai and Pissarides [2007] developed a general multi-sector model of growth with uneven shifts in the production frontier of the economy. They show that such an economy is consistent with the observation that the aggregate ratios of macro variables are constant with complete independence of the demand side and the supply side of the economy. Boppart [2011] extends a similar framework to incorporate relative price changes due to uneven sectoral growth. In our case, relative 
prices changes can occur due to uneven productivity shocks. But that will have no bearing on the effects of the monetary policies in the short run. These focus on mostly on the multi-sector structures of the economy. Buera and Kaboski [2009] argues that a usual two-sector model augmented with home production and human capital is better suited to match the data on structural change. This literature as is evident from above, focused almost exclusively on developed countries where internal labor and capital markets are relatively flexible and the consumption patterns of households are comparable. Our approach differs in both aspects. The other major difference is that we consider the economy in the short-run trying to account for inflationary behavior rather than taking a long run view of the growth process. In other words, we are concerned about the fluctuations around the growth path rather than the growth path itself.

\section{The model}

There are two parts of the economy linked via trade and the resultant money flow. I will denote them by $U$ and $R$ for urban and rural respectively. The urban economy produces manufactured goods and services whereas the rural economy produces agricultural goods and a 'land service'. Agricultural activities are not as machine-intensive as manufacturing or service production (think of metal industries or information technology industries). However, agriculture requires cultivable land. Even though this can be assumed to be exogenous, we note that the farmers have to spend a huge amount of labor and capital on the land itself making it suitable for production purpose. Also this is usually done keeping in mind a long-term goal as one piece of land prepared for growing one type of crop can be entirely unsuitable for growing a different variety for multiple years. Thus land provides a service over a period of time. There are other types of capital goods for the rural people. For keeping track of the model, all such lands, capital stocks and services are bundled and we call it 'land service'. Below, I describe the urban and the rural economy in details. 


\subsection{The urban households}

There is an unit mass of households in the urban sector. Let us define the lifetime utility function of the a representative household of the urban sector,

$U_{u}=\sum_{t=0}^{\infty} \beta^{t} E_{0}\left(\alpha_{u}\left(\beta_{u r} \log \left(C_{u}^{f}(t)\right)+\beta_{u u} \log \left(C_{u}^{s}(t)\right)\right)+\left(1-\alpha_{u}\right) \log \left(C_{u}^{m}(t)\right)-B L_{u}(t)\right)$,

where $C_{u}^{f}$ and $C_{u}^{s}$ denote consumption of agricultural goods (food) and services (low-end). On the other hand, $C_{u}^{m}$ denotes consumption of the manufactured goods and high-end services and finally, $L_{u}$ denotes urban labor. The relative weights of consumption goods are denoted by the parameters in the utility function. The weight of the bundle of the traded goods relative to the non-traded manufactured goods is given by $\alpha_{u}$. Parameter $\beta_{u r}$ shows the weight of rural agricultural production in the urban consumer's traded goods' bundle. Smilarly, $\beta_{u u}$ is the weight assigned by the urban households to their own productions, which can also be expressed as $1-\beta_{u r}$.

I assume that the households are liquidity constrained. We denote the level of money-holding by $M_{j}$ where the subscript $j$ denotes either urban or rural sector $(j \in\{U, R\})$. First, while trading with service for agricultural goods, there would be an outflow or inflow of liquidity. In the market for manufactured goods, the rest of the liquidity is spent for purchasing purpose. Finally, there is a flow budget constraint that keeps track of present versus future consumption (a sacrifice in consumption is needed for the next period's capital stock and hence, consumption). Following standard notations, the relevant budget constraints are as follows:

$$
\begin{aligned}
P^{s}(t) C_{u}^{s}(t)+P^{f}(t) C_{u}^{f}(t)+P^{m}(t) C_{u}^{m}(t)= & M_{u}(t-1)+P^{s}(t) y_{u}^{s}(t)+\epsilon_{u}(t), \\
K_{u}(t+1)+\frac{M_{u}(t)}{P^{m}(t)}= & w_{u}(t) L_{u}(t)+r_{u}(t) K_{u}(t) \\
& +(1-\delta) K_{u}(t)+\xi_{u}(t)
\end{aligned}
$$

The first constraint is nothing but the liquidity constraint which says total expenditure (services, agricultural and manufacturing respectively) has to be equal to total cash available. The second equation shows the dynamic trade-off. Capital next period plus real balance has to be equal to total earning in real terms which comprises wages, rental income, undepreciated capital stock as well as profit accrued to the firms (owned by the households) 
respectively. The market structure is monopolistic competition and hence the profit earned is non-zero. The addition of liquidity $\epsilon_{u}$ is treated as a lump-sum transfer made by the government to the households and therefore it does not affect the decision-making process. We assume that the liquidity constraint always binds by assuming that the growth rate is greater than the discount factor $\beta$. We will solve the model assuming a simple form of liquidity injection viz., $\epsilon_{u}(t)=\left(g_{u}^{\text {exog }}(t)-1\right) M_{u}(t)$ where the growth rate $g_{u}^{\text {exog }}(t)$ follows some stochastic process with mean 1 . Due to this shocks in growth rates, actual liquidity level also becomes stochastic.

\subsection{The urban supply side}

There are two production processes in the urban sectors; one that is bought and consumed by the farmers as well as the urban consumers (one can think of service products that are for direct consumption like transportation service) and the other is solely consumed and accumulated as capital stock by the urban consumers (for example, manufactured goods or housing).

\subsubsection{Low-end services}

Basically these are traded for the agricultural goods. The production of lowend services is assumed to have a very simple form. Note that service goods like transportation are non-storable. Each individual $i$ receives a stochastic production shock $\left(y_{i s}\right)$ drawn from positive support with well defined distribution and the final good is a combination of all individual productions and available fixed structures $\left(H_{s}\right)$,

$$
Y_{u}^{s}(t)=H_{s t} \int_{0}^{1} y_{i s}(t) d i
$$

with $y_{i s}(t)$ is distributed according to some distribution $f($.$) with positive$ support and finite moments. Therefore, $Y_{u}^{s}(t)$ is potentially a time-dependent variable though we will show that it does not have any bearing on the inflationary dynamics. Prices of service products will be determined through the trading in a competitive market between the urban and the rural economy.

\subsubsection{Manufacturing and services}

For a labeling purpose, we aggregate all types of manufacturing and highend service (i.e. which are not traded with the rural workers) and call it 
'manufacturing'. We follow a Calvo-type model specification of the supply side of the urban-specific goods where there is a perfectly competitive firms producing final goods and monopolistically competitive firms producing intermediate goods. As usual, the final goods sector bundles the intermediate goods using a standard bundling technology with Dixit-Stiglitz specification. Intermediate goods are produced with capital and labor supplied by the urban households who are the firm owners as well. Clearly in a monopolistic competition set-up, they will earn a positive profit. The final pricing equation will incorporate the stickyness.

\section{Final goods firm}

There is a continuum of firms supplying differentiated intermediates to the final goods producing firms. The bundling technology used by the firms is given by the following CES function:

$$
Y_{u t}^{m}=\left[\int_{0}^{1} Y_{u t}^{m}(k)^{\frac{\psi-1}{\psi}} d k\right]^{\frac{\psi}{\psi-1}}
$$

with $\psi>1$. A profit maximizing firm will choose to maximize

$$
\pi_{u t}^{m}=P_{t}^{m} Y_{u t}^{m}-\int_{0}^{1} P_{u t}^{m}(k) Y_{t}^{u}(k) d k,
$$

subject to the above bundling technology. As the final goods market is competitive, this profit eventually becomes zero. By solving the problem, the price index $P_{t}$ in the urban non-tradable sector has the usual form

$$
P_{u t}^{m}=\left[\int_{0}^{1} P_{u t}^{m}(k)^{\psi-1} d k\right]^{\psi-1} .
$$

The production function of the intermediate firm producing $k$-th variety is given by

$$
Y_{u t}^{m}(k)=\left(K_{t}^{u}(k)\right)^{\theta}\left(H_{t}^{u}(k)\right)^{1-\theta} .
$$

For the present purpose, without any loss of generalization we assume that there is no productivity shock. Assuming such a shock would not change the quanitity channel of inflation. Thus for simplicity, we ignore it. The aggregate pricing equation is given by,

$$
\left(P^{m}(t)\right)^{1-\psi}=\rho\left(P^{m}(t-1)\right)^{1-\psi}+(1-\rho)\left(\left(P^{m}(t)^{*}\right)^{1-\psi},\right.
$$

where $P^{m}(t)^{*}$ is optimally chosen by the firms having the chance to reset their price and $\rho$ is the fraction of firms getting the option to reset prices. 


\subsection{The rural households}

Similar to the urban sector there is an unit mass of households in the rural sector. The lifetime utility function of the a representative consumer of the rural sector is

$U_{r}=\sum_{t=0}^{\infty} \beta^{t} E_{0}\left(\alpha_{r}\left(\beta_{r r} \log \left(C_{r}^{f}(t)\right)+\beta_{r u} \log \left(C_{r}^{s}(t)\right)\right)+\left(1-\alpha_{r}\right) \log \left(C_{r}^{n}(t)\right)-B L_{r}(t)\right)$,

where $C_{r}^{f, s}$ is the composite consumption good comprising food and services. On the other hand, $C_{r}^{n}$ denotes consumption of the 'land service' and natural resources and finally, $L_{r}$ denotes rural labor. Rest of the structure of the consumption side remains the same. The relevant budget constraints are as follows:

$$
\begin{aligned}
P^{s}(t) C_{r}^{s}(t)+P^{f}(t) C_{r}^{f}(t)+P^{n}(t) C_{r}^{n}(t)= & M_{u}(t-1)+P^{f}(t) y_{r}^{f}(t)+\epsilon_{r}(t), \\
K_{r}(t+1)+\frac{M_{r}(t)}{P^{m}(t)}= & w_{r}(t) H_{r}(t)+r_{r}(t) K_{r}(t) \\
& +(1-\delta) L_{r}(t)+\xi_{r}(t) .
\end{aligned}
$$

The rural capital is often markedly different from the capital that urban households accumulate. For example Ref. Rosenzweig and Wolpin [1993] presents a case that rural capital accumulation in India can take place though investment in bullocks which are used as productive inputs for ploughing.

\section{4 the rural supply side}

There are two production processes; one that is bought and consumed by the farmers as well as the urban consumers (one can think of food-grains) and the other is solely consumed and accumulated by the rural consumers (for example, lands and natural resources which are replenishable to some extent).

\subsubsection{Food production}

Similar to the production of service goods, we impose a very simple mechanism for growing crops. The aggregate output is given as

$$
Y_{u}^{r}(t)=H_{r} q_{r}(t)
$$


where $H_{r}$ denotes quantity of all productive inputs and $q_{r}(t)$ denotes shortrun fluctuations meant to capture unknown factors affecting productivity such as weather conditions. Though it might affect the relative prices, it does not create inflation. Prices of agricultural products will be determined through the trading process between the urban and the rural economy.

\subsubsection{Land stock}

We are aggregating all rural households (land-owners as well as farmers) into one homogenous entity and broadly characterize the production side by a two-tier production structure as in the urban economy. Also for simplicity, we aggregate all types of capital and land services for the rural population into one good which we label as land stock. There is a continuum of producers supplying differentiated intermediate products to produce the final good i.e. land service. The bundling technology used by the land service producers is given by the following:

$$
Y_{u t}^{n}=\left[\int_{0}^{1} Y_{r t}^{n}(k)^{\frac{\psi-1}{\psi}} d k\right]^{\frac{\psi}{\psi-1}}
$$

with $\psi>1$. Similar to the production structure of the urban economy, we assume that profit maximizing rural producers will choose to maximize

$$
\pi_{r t}^{n}=P_{r t}^{n} Y_{r t}^{n}-\int_{0}^{1} P_{r t}^{n}(k) Y_{r t}^{n}(k) d k
$$

subject to the above bundling technology. As the final goods market is competitive, this profit has to be zero. The price index has the usual form

$$
P_{r t}^{n}=\left[\int_{0}^{1} P_{r t}^{n}(k)^{\psi-1} d k\right]^{\psi-1} .
$$

The production function of the intermediate firm producing $k$-th variety is given by

$$
Y_{r t}^{n}(k)=\left(K_{t}^{r}(k)\right)^{\theta}\left(L_{t}^{r}(k)\right)^{1-\theta} .
$$

Similar to the urban economy, the aggregate pricing equation is given by

$$
\left(P^{n}(t)\right)^{1-\psi}=\rho\left(P^{n}(t-1)\right)^{1-\psi}+(1-\rho)\left(\left(P^{n}(t)\right)^{*}\right)^{1-\psi},
$$

where $P^{n}(t)^{*}$ is the new optimal price. 
Note that in principle, the parameters could be set differently for the urban and the rural economies. However, we assume them to be symmetric in order to allow only one type of asymmetry in the model in the form of preferences of urban and rural households to capture the changing consumption pattern. Given a particular preference structure, this symmetry in the production structure will allow us to pin down the effects of monetary policies very easily as we will show below.

\subsection{Equilibrium configuration}

Now we can define the equilibrium in the economy.

1. Both the urban and rural households maximize their lifetime utility subject to their respective budget constraints.

2. Markets for all goods clear.

3. Given the aggregate liquidity which is governed by the monetary authority, liquidity available to the urban and rural households are pinned down.

4. Markets for labor and capital clear in both rural and the urban parts of the economy.

\section{$3 \quad$ Effects of monetary policies}

Since the economy is characterized by money, we interpret the monetary policies in terms of shocks in level or in growth rate. The monetary policies are implemented in the advanced, urban sector. The rural sector receives part of the shock through trade with the advanced sector.

Evolution of the stocks of money in the urban and the rural economy are given by the following dynamic process,

$$
\left[\begin{array}{l}
M_{u}(t+1) \\
M_{r}(t+1)
\end{array}\right]=\Phi \cdot\left[\begin{array}{l}
M_{u}(t) \\
M_{r}(t)
\end{array}\right]+\left[\begin{array}{l}
\epsilon_{u}(t+1) \\
\epsilon_{r}(t+1)
\end{array}\right]
$$


where

$$
\begin{aligned}
\Phi= & {\left[\begin{array}{cc}
1-\alpha_{u} & 0 \\
0 & 1-\alpha_{r}
\end{array}\right]+\left[\begin{array}{cc}
1-\alpha_{u} & 0 \\
0 & 1-\alpha_{r}
\end{array}\right] \times\left[\begin{array}{cc}
1-\alpha_{u} \beta_{u u} & -\alpha_{r} \beta_{r u} \\
-\alpha_{u} \beta_{u r} & 1-\alpha_{r} \beta_{r r}
\end{array}\right]^{-1} \times } \\
& {\left[\begin{array}{cc}
\alpha_{u} \beta_{u u} & -\alpha_{r} \beta_{r u} \\
-\alpha_{u} \beta_{u r} & \alpha_{r} \beta_{r r}
\end{array}\right] }
\end{aligned}
$$

and $\epsilon$ are monetary shocks. We provide a derivation in App. 7.1 .3 (full derivation in 7.1 ). In case the policy executed in the urban economy only, $\epsilon_{r}=0$.

\subsection{Dynamics of money flow}

We can rewrite the transition matrix as

$$
\Phi=V E V^{-1}
$$

where $E$ is a diagonal matrix containing the eigenvalues

$$
\begin{aligned}
e_{1} & =1 \\
e_{2} & =\frac{1+\alpha_{u} \alpha_{r}-\alpha_{u}-\alpha_{r}}{1+\alpha_{u} \alpha_{r}\left(\beta_{u u}+\beta_{r r}\right)-\alpha_{u} \alpha_{r}-\alpha_{u} \beta_{u u}-\alpha_{r} \beta_{r r}}
\end{aligned}
$$

and $V$ is a square matrix containing the corresponding eigenvectors. We can show easily that $e_{1}>e_{2}$ (see App. 7.2).

Proposition 1. The corresponding steady state money-holding is given by the following,

$$
\begin{aligned}
M_{u} & =\frac{\alpha_{r}\left(1-\alpha_{u}\right) \beta_{r u}}{\alpha_{r}\left(1-\alpha_{u}\right) \beta_{r u}+\alpha_{u}\left(1-\alpha_{r}\right) \beta_{u r}} \bar{M}, \\
M_{r} & =\frac{\alpha_{u}\left(1-\alpha_{r}\right) \beta_{u r}}{\alpha_{r}\left(1-\alpha_{u}\right) \beta_{r u}+\alpha_{u}\left(1-\alpha_{r}\right) \beta_{u r}} \bar{M}
\end{aligned}
$$

where $\bar{M}$ is the aggregate stock of money in absence of any exogenous shocks $(\epsilon=0$ in Eqn. 17).

Proposition 2. The equilibrium distribution is globally stable. 
In other words, given any initial level of aggregate money supply, the economy will converge to the equilibrium.

A proof is provided below. Note that the system is driven by the matrix $\Phi$ which can be decomposed as $\Phi=V E V^{-1}$ where $V$ contains the eigenvectors and $E$ is a diagonal matrix containing the eigenvalues. Using the eigendecomposition repeatedly, we can write

$$
\begin{aligned}
M(t+1) & =\Phi M(t) \\
& =V E V^{-1} M(t) \\
& =V E V^{-1} V E V^{-1} M(t-1) \\
& =V E^{2} V^{-1} M(t-1) \\
& \vdots \\
& =V E^{t+1} V^{-1} M(0) .
\end{aligned}
$$

Note that since the aggregate stock of money is given (recall from Eqn 20 that the largest eigenvalue is 1 ),

$$
\lim _{t \rightarrow \infty} E^{t}=\left[\begin{array}{ll}
1 & 0 \\
0 & 0
\end{array}\right] .
$$

Thus it converges to the eigenvector corresponding to the eigenvalue 1 . Recognizing that $\Phi$ is a Markov chain makes it easy to show convergence (see e.g. Ljungqvist and Sargent [2004]).

Table 3 reports the values of the parameters selected to model the economy. For simplicity, we assume that both the urban and the rural sectors are identical in terms of preferences and production structures. While it can be argued that there could be significant differences between the two, we make them identical in order to present a cleaner perspective on the effects of monetary shocks.

\section{Sectoral dispersion of monetary shocks}

Traditionally monetary authority implements the policies in the urban sector. In developed economies with almost fully formal labor markets and free flow of capital within economy, the assumption of a single sector economy is realistic as is assumed in the literature (see any textbook treatment e.g. Walsh [2010]). But for the emerging economies or the poorer ones, there 


\begin{tabular}{|l|c|l|}
\hline Description & Parameter & Value \\
\hline \hline Disutility parameter & $B$ & -2.5805 \\
Weights in the utility function* & $\alpha_{x}, \beta_{x y}$ & 0.5 \\
Discount factor & $\beta$ & 0.99 \\
Rate of depreciation & $\delta$ & 0.025 \\
Share of capital in output & $\theta$ & 0.36 \\
Degree of price stickyness & $\rho$ & 0.75 \\
Mark-up factor & $\psi$ & 11 \\
Persistence of money growth rate shock & $\gamma$ & 0.48 \\
\hline
\end{tabular}

Table 3: Values of the parameters describing the rural and the urban economy in the baseline calibration. ${ }^{*}$ The weights in the utility function are indexed by the urban and rural sectors viz. $x, y \in\{u, r\}$.

is gross violation of this assumption as it is hard to imagine a representative household in an economy characterized by huge dispersion in sectoral activities, capital accumulation process and so forth.

It is worthwhile to recall that the basic argument in Basu [2011] is the quantity theoretic channel of monetary expansion which posits that opening of branches by the governmental/private banks into the rural area would bring a large quantity of money that was lying idle into circulation. There are various reasons why the rural economy is effectively isolated even in terms of the monetary flows from the formal, urban economy. The most important factor is the lack of formal banking system which basically forces rural employees to save money under the mattress instead of earning interest income out of deposits. Thus when banks branch out, then people would deposit their money for a safer and positive return rather than eroding its value over time due to inflation.

\subsection{Effects of expansionary monetary policy}

Now we are in a position to study the effects of expansionary monetary policies conducted and executed in the urban sector. Note that the urban households have their own decision making process which is separate from the rural households' decision making process. The only link between these two sectors is through trade and the resultant flow of money. In steady state, if there is a monetary expansion in the urban sector, it temporarily relaxes 
the liquidity constraint that the urban households face. Prices are sticky and hence do not adjust as rapidly to nullify the effects. Thus the demand for goods and services by the urban households increases. But since this pushes the system out of equilibrium, when trade occurs between with rural households, a part of that excess liquidity trickles in the rural sector. This simultaneously contracts the liquidity constraint of the urban households and relaxes the same for the rural households. This phenomenon continues till the economy again reaches the new steady state with higher amount of nominal money and higher prices. Here we emphasize that in the current model, we assume no productivity shocks. Thus the all variables responds to monetary shocks only.

Fig. 2 presents the impulse response functions of a single sector economy with capital accumulation operating under liquidity constraint. Note that the monetary shock in this case is a shock at level, not at growth rate of money, causing the up and down sharp spikes since a shock at level would imply first a positive shock in the growth rate followed by a negative shock in the same. Here we describe the aggregate responses of the variables. For an economy, $Y$ denotes the aggregate output i.e. tradables plus non-tradables evaluated at constant relative prices. Note that if there is no productivity shocks, production of tradables are constant and hence do not fluctuate. Thus the aggregate response arises solely out of the non-tradables (Manufacturing in the urban economy, land service in the rural economy). Fluctuations in the total consumption $C$ is also explained the same way. The way the model is constructed capital $K$, labor $L$, wage $w$ and rental rate $r$ are specific to the production of the non-tradable sector.

Fig. 3 shows the effects over time of monetary expansion in the urban sector. The next figure (Fig. 4) is the most interesting one. It shows how monetary shocks percolate from the urban to the rural economy causing fluctuations in real variables. This is a second-order effect as the rural economy does not get hit by the shock directly. However, as is clear from the impulse response functions, the real variables do show substantial amount of fluctuations. The next three figures (Fig. 5, 6, 7) show the same as above except that now the economy receives shocks at the growth rates rather than at levels. The results are qualitatively similar. The responses are smoother as it takes a while before a shock at the growth rate dies down due to persistence (Table 3). 

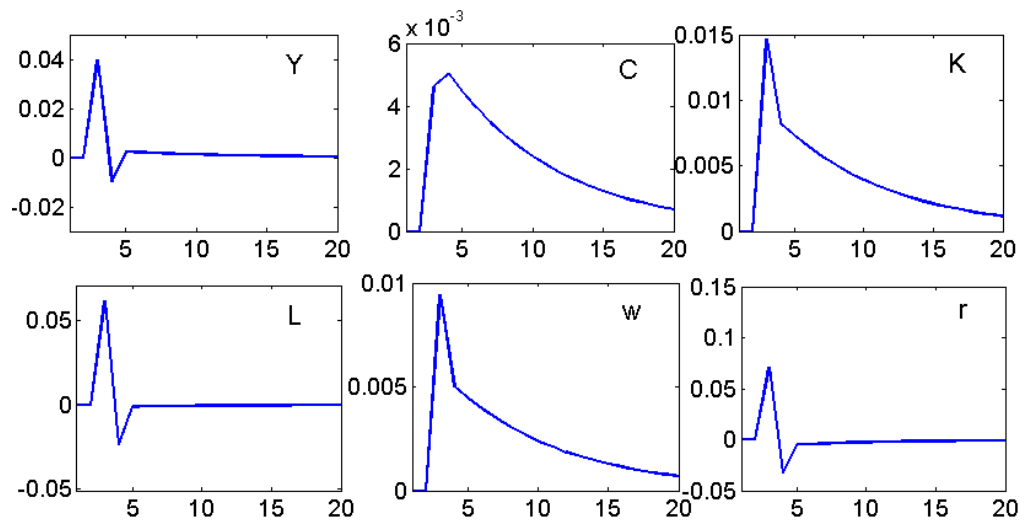

Figure 2: Benchmark: Impulse response functions in the urban economy for positive monetary shock (.5\% in level) in a one sector economy.
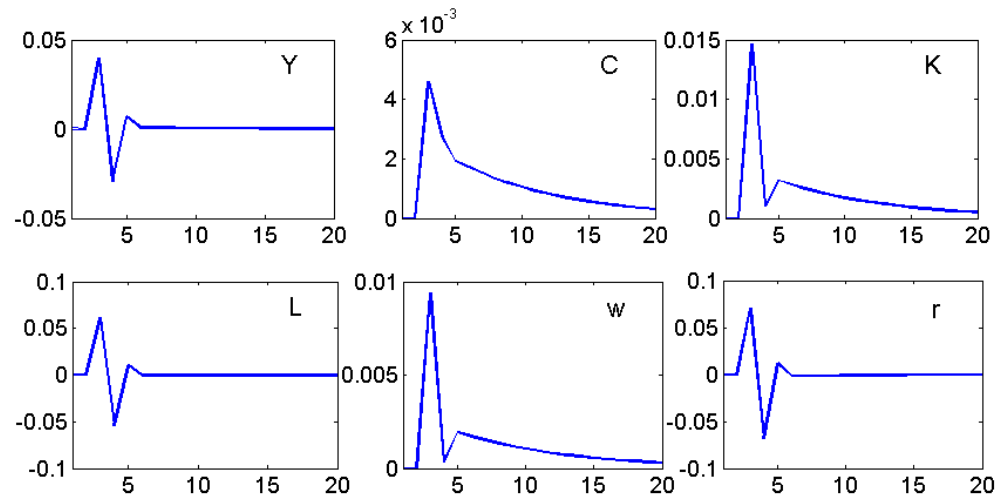

Figure 3: Impulse response functions in the urban economy for positive monetary shock (.5\% in level) in the urban area. 

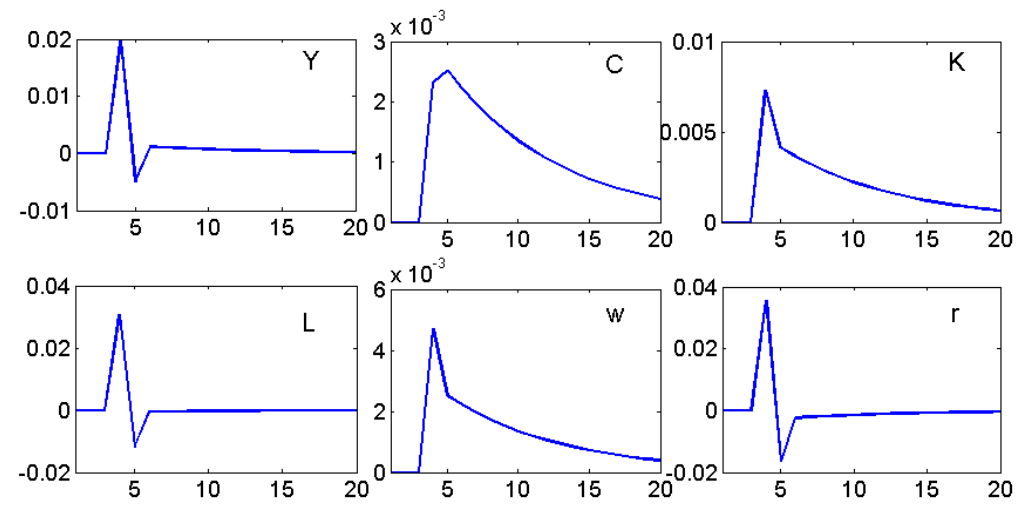

Figure 4: Impulse response functions in the rural economy for positive monetary shock $(.5 \%$ in level) in the urban area.
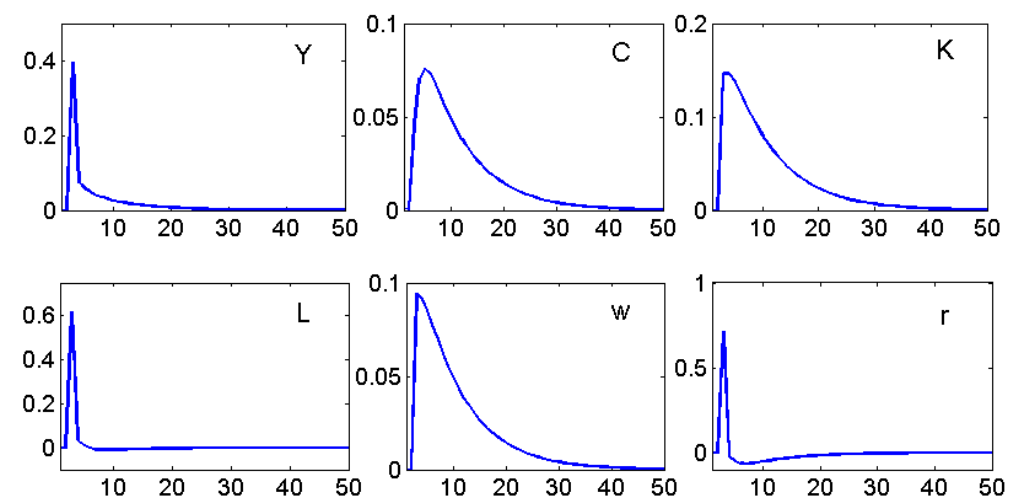

Figure 5: Benchmark: impulse response functions in the urban economy for positive shock in growth rate of money in a single sector economy. 

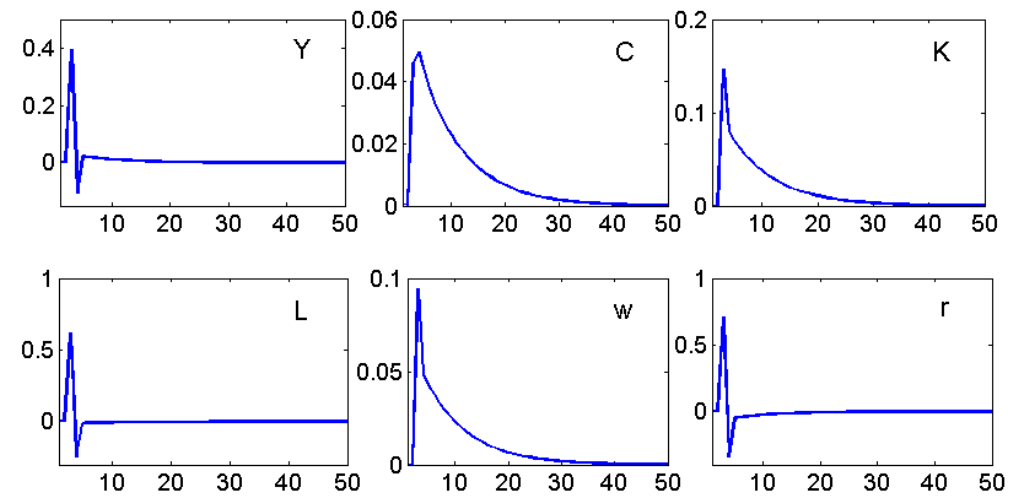

Figure 6: Impulse response functions in the urban economy for positive shock in growth rate in the urban area.
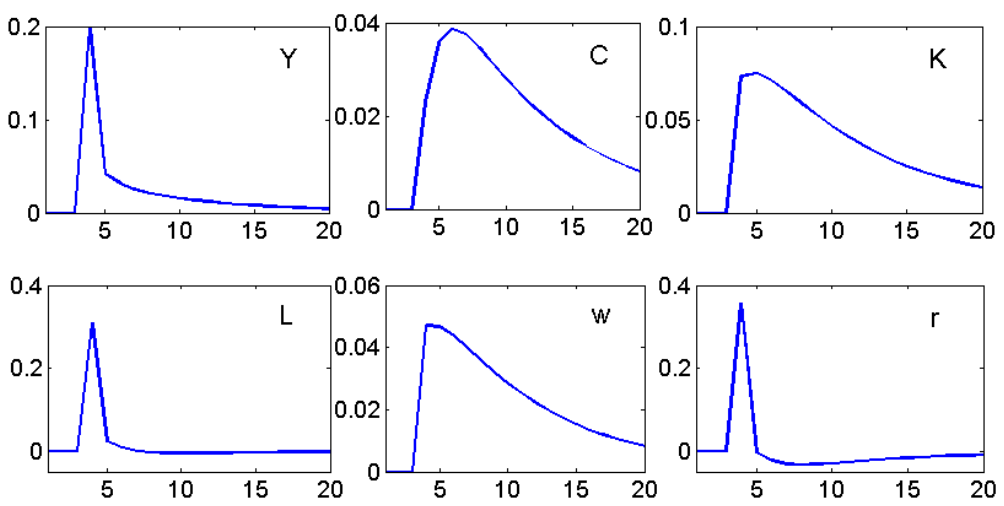

Figure 7: Impulse response functions in the rural economy for positive persistent money shock in the urban area. 


\subsection{Inflationary effects of expansion of banking ser- vices in the rural economy}

The main point of this whole exercise is to show that financial inclusion can create bouts of inflation. The mechanism mainly rests on quantity theory of money. What is interesting is that this mechanism does not generate permanently higher level of inflation. Instead, it creates inflationary pressure only as long as the expansionary phase continues. Since prices are sticky, it takes a while before prices catch-up. Bur once it does, there is no excess upward pressure on inflation. This is a very important point to consider as it distinguishes short-term and long-term inflation. Also, due to the shortness of inflationary activity, it should not generate any further inflationary expectation which might have long lasting effects. Thus from the policy-makers point of view, it should not be a concern from a sufficiently long term perspective.

\section{$5 \quad$ Structural changes and liquidity effects}

From Eqn. 21 we see that relative money holding is fully determined by the parameters of the utility function. The intuition of this finding can be traced back to the assumption that in this economy money is used to carry out trade of goods and services. Consequently, preferences over tradables and non-tradables determine the equilibrium distribution of money. Due to changes in preference parameters, the equilibrium distribution of money across sectors would change.

\subsection{Comparative statics}

In this section, we do a set of comparative statics to understand the magnitude and the directions of changes in the equilibrium distribution due to changes in the relative weights of consumption bundles.

Proposition 3. If the urban households prefer manufactured goods more compared to the bundle of service products and agricultural goods, then urban households will hold more money in equilibrium.

Proof: Assigning higher weights to manufactured goods implies $\alpha_{u}$ decreases. We can show that

$$
\frac{\delta M_{u}}{\delta \alpha_{u}}<0
$$


Recall from Eqn. 21 that

$$
M_{u}=\frac{\alpha_{r}\left(1-\alpha_{u}\right) \beta_{r u}}{\alpha_{r}\left(1-\alpha_{u}\right) \beta_{r u}+\alpha_{u}\left(1-\alpha_{r}\right) \beta_{u r}} \bar{M} .
$$

By differentiation we get,

$$
\begin{aligned}
\frac{\delta M_{u}}{\delta \alpha_{u}} & =\frac{-\alpha_{r} \beta_{r u}\left(\alpha_{r}\left(1-\alpha_{u}\right) \beta_{r u}+\alpha_{u}\left(1-\alpha_{r}\right) \beta_{u r}\right)-\alpha_{r}\left(1-\alpha_{u}\right) \beta_{r u}\left(-\alpha_{r} \beta_{r u}+\left(1-\alpha_{r}\right) \beta_{u r}\right)}{\left(\alpha_{r}\left(1-\alpha_{u}\right) \beta_{r u}+\alpha_{u}\left(1-\alpha_{r}\right) \beta_{u r}\right)^{2}} \bar{M} \\
& =\frac{-\alpha_{r} \beta_{r u} \alpha_{u}\left(1-\alpha_{r}\right) \beta_{u r}-\alpha_{r}\left(1-\alpha_{u}\right) \beta_{r u}\left(1-\alpha_{r}\right) \beta_{u r}}{\left(\alpha_{r}\left(1-\alpha_{u}\right) \beta_{r u}+\alpha_{u}\left(1-\alpha_{r}\right) \beta_{u r}\right)^{2}} \bar{M} \\
& =\frac{-\alpha_{r} \beta_{r u}\left(1-\alpha_{r}\right) \beta_{u r}}{\left(\alpha_{r}\left(1-\alpha_{u}\right) \beta_{r u}+\alpha_{u}\left(1-\alpha_{r}\right) \beta_{u r}\right)^{2}} \bar{M}
\end{aligned}
$$

Therefore, for positive weights attached to all consumption goods,

$$
\frac{\delta M_{u}}{\delta \alpha_{u}}<0
$$

It is noteworthy that by definition,

$$
M_{u}+M_{r}=\bar{M}
$$

that is aggregate stock of money is distributed amone the rural and the urban households. Thus if the urban consumers increase money holding, the rural consumers have to reduce it one-for-one.

Proposition 4. If rural households assign bigger weight to rural capital goods, then rural households will increase and the urban households will reduce liquidity holding. In other words following similar calculations as above, we can show that

$$
\frac{\delta M_{r}}{\delta \alpha_{r}}<0 \text { and } \frac{\delta M_{u}}{\delta \alpha_{r}}>0 .
$$

Proposition 5. If urban households assign bigger weight to agricultural goods, then they will reduce and the rural households increase money holding in equilibrium. In other words,

$$
\frac{\delta M_{u}}{\delta \beta_{u r}}<0 \text { and } \frac{\delta M_{r}}{\delta \beta_{u r}}>0
$$


Proposition 6. If the rural households assign bigger weight to service goods, then they would reduce and the urban households increase money-holding in equilibrium. In other words,

$$
\frac{\delta M_{r}}{\delta \beta_{r u}}<0 \text { and } \frac{\delta M_{u}}{\delta \beta_{r u}}>0 .
$$

All of these propositions can be proved similar to the way Proposition 3 is proved. For detailed proofs, see App. 7.3.

\subsection{Time-varying effects of monetary shocks}

As mentioned before, a strand of the literature on structural change emphasizes the changes in relative preference over time to capture the shifts in consumption and production patterns. Since in the current world, we are observing a much rapid shift in the consumption profile than in production, we make parametric variations in the utility functions to capture relative movements of consumption bundle in equilibrium. It is worthwhile to note that reallocation of labor from agriculture to manufacturing/service entails huge fixed costs in terms of human capital development making the process much slower than changes in consumption pattern. Therefore, this exercise allows us to understand the effects on consumption pattern without altering the labor allocation and consequently trace out the effects of monetary policies in the usual business cycle frequency.

We show the responses of the variables in Fig. 8 and 9 with structural changes where land service (the capital good for the rural economy) has lesser importance assigning more weight to the service products. As the relative weight increases in favor of service products (baseline: 0.5, new: 0.67), the responses of the real variables change as the equilibrium distribution changes.

The differences in the impulse response functions are qualitatively important. They show that as both urban and rural households with structural change, the urban economy becomes more robust to the liquidity shocks (because of liquidity stock grows) and the rural economy becomes more volatile (with shrinking stock). Quantitatively the results do not show very significant differences in the present simulation as we have changed only the rural households' consumption bundle. Further changes in the urban consumption bundle reducing weight of agricultural products, would induce bigger dispersion between the pre-change (i.e. baseline) and post-change responses. 

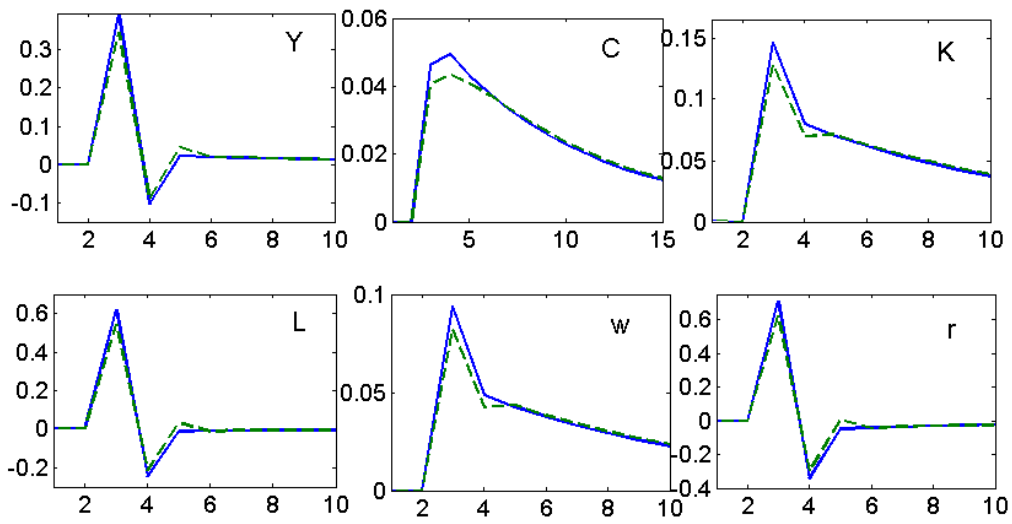

Figure 8: Comparison of impulse response functions in the urban economy with structural change. Thick line: responses of the original multi-sector economy, dotted line: same with structural changes.
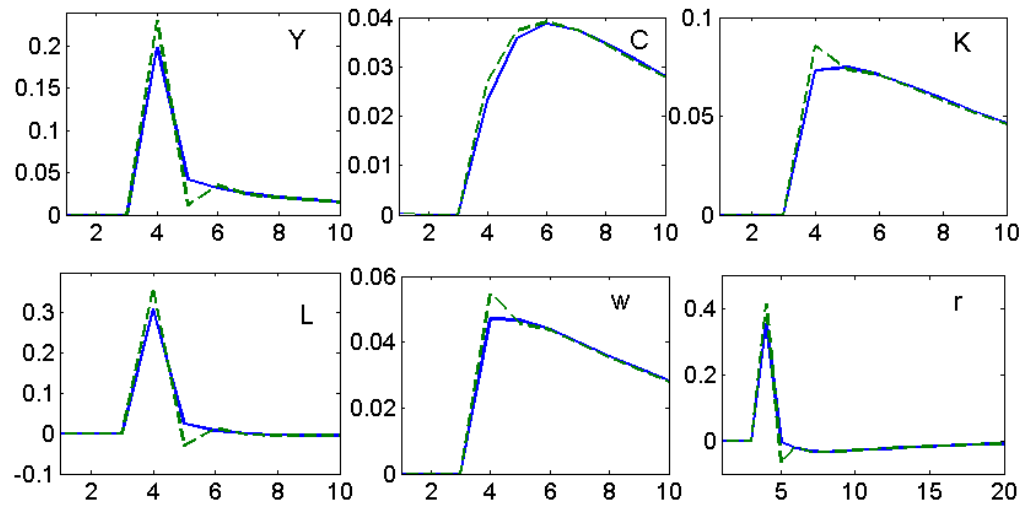

Figure 9: Comparison of impulse response functions in the rural economy with structural change. Thick line: responses of the original multi-sector economy, dotted line: same with structural changes. 


\section{Conclusion}

In this paper, we have presented a framework to understand the impacts of monetary policies in a dual market set-up that are mostly seen in emerging markets. The issue of temporary inflation and its causes have frequently come up while setting policies in such economies (Basu [2011]). Here we formulate a model to pin down the spill-over effects on the real variables. We find that there is substantial cross-sectional spill-over effects of monetary policies which creates inflationary pressure simultaneously in the urban and the rural economy even though it is executed mostly in the former. Due to similar reasons, we show that financial inclusion creates bouts of inflation purely through a quantity channel. But these are of temporary nature implying that for setting inflationary targets this should not be much of an issue even though in short run it may induce more volatility than is predicted by the standard one-sector models.

\section{Appendix}

\subsection{Mathematical derivations}

\subsubsection{First order conditions for non-tradables}

The first order conditions give the following dynamic system of equations for the urban economy:

$$
\begin{aligned}
\frac{1}{w_{u}(t)} & =\beta E\left(\frac{1}{w_{u}(t+1)}\left(r_{u}(t+1)+(1-\delta)\right)\right. \\
-\frac{B}{w_{u}(t) P^{m}(t)} & =\beta(1-\alpha) E\left(\frac{1}{P^{m}(t+1) C_{u}^{m}(t)}\right)
\end{aligned}
$$

For the rural economy, we get a similar set of equations showing the optimality conditions between consumption and savings for the rural households.

\subsubsection{Market clearance for service and agricultural goods}

To solve for the equilibrium prices $P^{s}$ and $P^{f}$, we need to impose the market clearing conditions. We also assume without any loss of generalization that

there is no monetary shock. From the first order conditions and the budget 
equation, we know that total expenditure on the service good by the rural workers is

$$
P^{s}(t) C_{r}^{s}(t)=\alpha_{r} \beta_{r u}\left(P^{f}(t) Y_{r}^{f}(t)+M_{r}(t-1)\right) .
$$

A similar equation describes the demand for the demand by the urban consumers for agricultural goods. Market-clearing for agricultural and service products simply requires the following conditions to hold,

$$
\begin{aligned}
& Y_{r}^{f}(t)=C_{u}^{f}(t)+C_{r}^{f}(t) \\
& Y_{u}^{s}(t)=C_{u}^{s}(t)+C_{s}^{f}(t) .
\end{aligned}
$$

\subsubsection{Money flow equations}

First, the solution of the model without exogenous shocks is shown. In the next step, we add that shock. Let us denote the expenditures $P^{f} Y_{r}^{f}$ and $P^{s} Y_{u}^{s}$ by $x_{r}$ and $x_{u}$ respectively. Let $X=\left\{x_{u}, x_{r}\right\}^{T}$ and $M(t)=\left\{M_{u}, M_{r}\right\}^{T}$. Therefore,

$$
X(t)=\Gamma(X(t)+M(t-1))
$$

where

$$
\Gamma=\left[\begin{array}{ll}
\alpha_{u} \beta_{u u} & \alpha_{r} \beta_{r u} \\
\alpha_{u} \beta_{u r} & \alpha_{r} \beta_{r r}
\end{array}\right] .
$$

We define $D_{1-\alpha}$ as a diagonal matrix with elements of the vector $1-\alpha=$ $\left\{1-\alpha_{u}, 1-\alpha_{r}\right\}$ along the diagonal. Then the solution can be written as

$$
X(t)=(I-\Gamma)^{-1} \Gamma M(t-1) .
$$

By substituting the solution into the demand for money equation (which arises because the households are liquidity constrained), we get

$$
\begin{aligned}
M(t) & =D_{1-\alpha} M(t-1)+D_{1-\alpha} X \\
& =D_{1-\alpha} M(t-1)+D_{1-\alpha}(I-\Gamma)^{-1} Q M(t-1) \\
& =\left(D_{1-\alpha}+D_{1-\alpha}(I-\Gamma)^{-1} \Gamma\right) M(t-1) \\
& =\Phi M(t-1),
\end{aligned}
$$

where $\Phi=\left(D_{1-\alpha}+D_{1-\alpha}(I-\Gamma)^{-1} \Gamma\right)$ is the transition matrix. By forwarding one-period, we get

$$
M(t+1)=\Phi M(t) .
$$

If we include the exogenous liquidity shocks, the process can be rewritten as

$$
M(t+1)=\Phi M(t)+\epsilon,
$$

where $\epsilon$ is a vector of shocks. 


\subsubsection{The aggregate model for the urban economy}

Full system of equations for the urban economy:

$$
\begin{aligned}
\frac{1}{\beta} & =E\left[\frac{w_{u}(t)}{w_{u}(t+1)}\left(r_{u}(t+1)+1-\delta\right)\right] \\
\frac{B}{w_{u}(t) P^{m}(t)} & =E\left(\frac{\alpha \beta}{P^{m}(t+1) C_{u}^{m}(t+1)}\right) \\
P^{m}(t) C_{u}^{m}(t) & =g_{u}(t) M_{u}(t-1) \\
K_{u}(t+1)+\frac{M_{u}(t)}{P^{m}(t)} & =Y_{u}^{m}(t)+(1-\delta) K_{u}(t) \\
P^{* k} & =\frac{\psi}{\psi-1} \frac{\left.E_{t} \sum_{i=0}^{\infty}(\beta \rho)^{i} P_{u}^{m}(t+i) Y_{(}^{m} t+i\right)(k) \frac{w_{u}(t+i)}{(1-\theta) \lambda_{t+i}}\left[\frac{r_{u}(t+i)(1-\theta)}{w_{u}(t+i) \theta}\right]}{E+t \sum_{i=0}^{\infty}(\beta \rho)^{i} Y_{u}^{m}(t+i)(k)} \\
\left(P^{m}(t)\right)^{1-\psi} & =\rho\left(P^{m}(t-1)\right)^{1-\psi}+(1-\rho)\left(P^{m^{*}}(t)\right)^{1-\psi} \\
M_{u}(t) & =g_{u}(t) M_{u}(t-1)
\end{aligned}
$$

A similar set of equations describe the evolution of the rural economy.

\section{$7.2 \quad$ Eigenvalues}

Claim: $e_{1} \geq e_{2}$.

Proof: Note that (Prop. 1)

$$
\begin{aligned}
e_{1} & =1 \\
e_{2} & =\frac{1+\alpha_{u} \alpha_{r}-\alpha_{u}-\alpha_{r}}{1+\alpha_{u} \alpha_{r}\left(\beta_{u u}+\beta_{r r}\right)-\alpha_{u} \alpha_{r}-\alpha_{u} \beta_{u u}-\alpha_{r} \beta_{r r}} .
\end{aligned}
$$

Therefore, we have to prove that

$$
1 \geq \frac{1+\alpha_{u} \alpha_{r}-\alpha_{u}-\alpha_{r}}{1+\alpha_{u} \alpha_{r}\left(\beta_{u u}+\beta_{r r}\right)-\alpha_{u} \alpha_{r}-\alpha_{u} \beta_{u u}-\alpha_{r} \beta_{r r}}
$$

$$
\begin{array}{ll}
\text { or } & 1+\alpha_{u} \alpha_{r}\left(\beta_{u u}+\beta_{r r}\right)-\alpha_{u} \alpha_{r}-\alpha_{u} \beta_{u u}-\alpha_{r} \beta_{r r} \geq 1+\alpha_{u} \alpha_{r}-\alpha_{u}-\alpha_{r}, \\
\text { or } & \alpha_{u} \alpha_{r}\left(\beta_{u u}+\beta_{r r}\right)-\alpha_{u} \alpha_{r}-\alpha_{u} \beta_{u u}-\alpha_{r} \beta_{r r} \geq \alpha_{u} \alpha_{r}-\alpha_{u}-\alpha_{r}, \\
\text { or } & \left(\alpha_{r}-1\right) \alpha_{u} \beta_{r r}+\left(\alpha_{u}-1\right) \alpha_{r} \beta_{u u} \geq \alpha_{u}\left(\alpha_{r}-1\right)+\alpha_{r}\left(\alpha_{u}-1\right), \\
\text { or } & \left(\alpha_{r}-1\right) \alpha_{u}\left(\beta_{r r}-1\right)+\left(\alpha_{u}-1\right) \alpha_{r}\left(\beta_{u u}-1\right) \geq 0, \\
\text { or } & \left(1-\alpha_{r}\right) \alpha_{u}\left(1-\beta_{r r}\right)+\left(1-\alpha_{u}\right) \alpha_{r}\left(1-\beta_{u u}\right) \geq 0
\end{array}
$$


Given that all the weights in the utility functions are semi-positive but less than or equal to one, we see that the left hand side of the last expression is positive. Thus the proof concludes.

\subsection{Effects of changes in weights in the utility func- tions}

Claim: $\frac{\delta M_{r}}{\delta \alpha_{r}}<0$ and $\frac{\delta M_{u}}{\delta \alpha_{r}}>0$.

Proof: From Eqn. 21 we know that

$$
M_{r}=\frac{\alpha_{u}\left(1-\alpha_{r}\right) \beta_{u r}}{\alpha_{r}\left(1-\alpha_{u}\right) \beta_{r u}+\alpha_{u}\left(1-\alpha_{r}\right) \beta_{u r}} \bar{M} .
$$

Let us write

$$
\bar{D}=\frac{\bar{M}}{\left(\alpha_{r}\left(1-\alpha_{u}\right) \beta_{r u}+\alpha_{u}\left(1-\alpha_{r}\right) \beta_{u r}\right)^{2}}
$$

and note that $\bar{D}>0$ for positive weights.

Therefore we have,

$$
\begin{aligned}
\frac{\delta M_{r}}{\delta \alpha_{r}} & =\frac{-\alpha_{u} \beta_{u r}\left(\alpha_{r}\left(1-\alpha_{u}\right) \beta_{r u}+\alpha_{u}\left(1-\alpha_{r}\right) \beta_{u r}\right)-\alpha_{u}\left(1-\alpha_{r}\right) \beta_{u r}\left(\left(1-\alpha_{u}\right) \beta_{r u}-\alpha_{u} \beta_{u r}\right)}{\bar{D}} \\
& =\frac{-\alpha_{u} \beta_{u r} \alpha_{r}\left(1-\alpha_{u}\right) \beta_{r u}-\alpha_{u}\left(1-\alpha_{r}\right) \beta_{u r}\left(1-\alpha_{u}\right) \beta_{r u}}{\bar{D}} \\
& =-\frac{\alpha_{u} \beta_{u r}\left(1-\alpha_{u}\right) \beta_{r u}}{\bar{D}} \\
& <0 .
\end{aligned}
$$

Since $M_{u}+M_{r}=\bar{M}$, we immediately see that

$$
\frac{\delta M_{u}}{\delta \alpha_{r}}>0
$$

Claim: $\frac{\delta M_{u}}{\delta \beta_{u r}}<0$ and $\frac{\delta M_{r}}{\delta \beta_{u r}}>0$.

Proof: From Eqn. 21 we know that

$$
M_{u}=\frac{\alpha_{r}\left(1-\alpha_{u}\right) \beta_{r u}}{\alpha_{r}\left(1-\alpha_{u}\right) \beta_{r u}+\alpha_{u}\left(1-\alpha_{r}\right) \beta_{u r}} \bar{M} .
$$


Therefore,

$$
\begin{aligned}
\frac{\delta M_{u}}{\delta \beta_{u r}} & =-\frac{\alpha_{r}\left(1-\alpha_{u}\right) \beta_{r u} \alpha_{u}\left(1-\alpha_{r}\right)}{\bar{D}} \\
& <0
\end{aligned}
$$

The second inequality follows because $M_{u}+M_{r}=\bar{M}$.

Claim: $\frac{\delta M_{r}}{\delta \beta_{r u}}<0$ and $\frac{\delta M_{u}}{\delta \beta_{r u}}>0$

Proof: From Eqn. 21 we know that

$$
M_{r}=\frac{\alpha_{u}\left(1-\alpha_{r}\right) \beta_{u r}}{\alpha_{r}\left(1-\alpha_{u}\right) \beta_{r u}+\alpha_{u}\left(1-\alpha_{r}\right) \beta_{u r}} \bar{M} .
$$

Similar to the above calculation, we get

$$
\begin{aligned}
\frac{\delta M_{r}}{\delta \beta_{r u}} & =-\frac{\alpha_{u}\left(1-\alpha_{r}\right) \beta_{u r} \alpha_{r}\left(1-\alpha_{u}\right)}{\bar{D}} \\
& <0 .
\end{aligned}
$$

The second inequality follows from the same argument that $M_{u}+M_{r}=$ $\bar{M}$.

\section{References}

G. D. Bartolomeo and L. Rossi. Effectiveness of monetary policy and limited asset market participation: Neoclassical versus keynesian effects. International Journal of Economic Theory, 3(3):213218, 2007.

K. Basu. Understanding inflation and controlling it. Economic and Political Weekly, XLVI(41):50-64, 2011.

W. Baumol. Macroeconomics of unbalanced growth: the anatomy of urban crisis. American economic review, 57:415-426, 1967.

F. O. Bilbie. Limited asset markets participation, monetary policy and (inverted) aggregate demand logic. Journal of economic theory, 140(1): 162196, 2008. 
T. Boppart. Structural change, relative price effects and the kaldor facts in a growth model with non-gorman preferences. Technical report, University of Zurich (working paper), 2011.

F. Buera and J. Kaboski. Can traditional theories of structural change fit the data? Journal of the European Economic Association, 7:469-477, 2009.

G. Calvo. Staggered pricing in a utility-maximizing framework. Jounal of monetary economics, 12:383-98, 1983.

A. S. Chakrabarti. Essays on macroeconomic networks, volatility and labor allocation. PhD thesis, Boston University, 2015.

C. Echevarria. Changing sectoral composition associated with economic growth. International economic review, 38:431-452, 1997.

S. Kuznets. Quantitative aspects of the economic growth of nations: II. Economic development and cultural change, 4:3-111, 1957.

J. Laitner. Structural change and economic growth. Review of economic studies, 67:545-561, 2000.

L. Ljungqvist and T. Sargent. Recursive Macroeconomic Theory. MIT press, 2004.

A. Mehrotra and J. Yetman. Financial inclusion and optimal monetary policy. BIS Working Papers, 2014.

V. Midrigan and T. Philippon. Household leverage and the recession. Working paper, 2011.

L. R. Ngai and C. A. Pissarides. Structural change in a multisector model of growth. American Economic Review, 97:429-443, 2007.

L. L. Pasinetti. Structural change and economic growth : a theoretical essay on the dynamics of wealth of nations. Cambridge University Press, 1981.

E. S. Prasad. Distributional effects of macroeconomic policy choices in emerging market economies. IMF Economic Review, 62:409429, 2014. 
M. R. Rosenzweig and K. I. Wolpin. Credit market constraints, consumption smoothing, and the accumulation of durable production assets in lowincome countries: investments in bullocks in india. Journal of Political Economy, 101(2):223244, 1993.

R. Shukla. How India Earns, Spends and Saves. Sage publications, 2010.

Duvvuri Subbarao. Should banking be made boring? In Growth and Finance: Essays in Honour of Rangarajan. New Delhi: Academic Foundation, 2011.

Carl Walsh. Monetary Theory and Policy. MIT press, 2010.

S. D. Williamson. Monetary policy and distribution. Journal of monetary economics, 55:1038-1053, 2008.

World Bank. http://databank.worldbank.org/data//reports.aspx?source=2\&country= IND\&series $=\&$ period $=$. , . 